\title{
Herbal Medicine: Yesterday, Today and Tomorrow
}

\author{
Paul C. Chikezie ${ }^{1^{*}}$ and Okey A. Ojiako ${ }^{2}$
}

${ }^{1}$ Department of Biochemistry, Imo State University, Owerri, Nigeria

${ }^{2}$ Department of Biochemistry, Federal University of Technology, Owerri, Nigeria

*Corresponding author: Chikezie PC, Department of Biochemistry, Imo State University, Owerri, Nigeria, Tel: +2348038935327; E-mail: p_chikezie@yahoo.com

Received date: July 15, 2015, Accepted date: August 03, 2015, Published date: August 11, 2015

Copyright: (c) 2015, Chikezie PC et al. This is an open-access article distributed under the terms of the Creative Commons Attribution License, which permits unrestricted use, distribution, and reproduction in any medium, provided the original author and source are credited.

\begin{abstract}
Herbal medicines involve the integration of several therapeutic experiences and practices of indigenous systems of medicine that may span many previous generations, which often provides valuable guidelines to the selection, preparation and application of herbal formulation for the treatment, control and management of variety of ailments. According to World Health Organization, $60 \%$ of the world's population depends on traditional medicine and $80 \%$ of the population in developing countries depends almost entirely on traditional medicine practices and herbal medicines for their primary health care needs. As a result of increasing demand for herbal medicines, there are increasing concerns about the safety, standardization, efficacy, quality, availability and preservation of herbal products by policy-makers, health professionals as well as the general public. Improvement in the quality of herbal medicines could be achieved by deliberate implementation of good agricultural practices (GAPs) at the point of cultivation of medicinal plants and good manufacturing practices (GMPs) during the process of manufacture and packaging of finished herbal products, as well as post-marketing quality assurance surveillance. Additionally, following the current sustained improvements in quality control and regulatory measures in many countries of the world, it is envisaged that in the near future, herbal medicinal practices will be integrated into the conventional medicines.
\end{abstract}

Keywords: Herbal medicines; Herbal products; Phytochemicals; Standardization

\section{Introduction}

Herbal medicine, also called botanical medicine or phytomedicine, refers to the use of plant parts such as seeds, berries, roots, leaves, bark or flower for medicinal and therapeutic purposes [1,2]. Herbal medicines are associated with several therapeutic experiences and practices of indigenous systems of medicine, which serve as guidelines for the selection, preparation and application of herbal formulation to achieve therapeutic benefits. Alleviation of diseases and maintenance of good health using herbal medicines is as old as mankind and is the most popular form of healthcare practice known to humanity that has been practiced by all cultures in all ages throughout the history of civilization. Herbal medicine has evolved throughout the timeline of human civilization. The present commentary briefly described the existence of herbal medicine in pre-historic/ancient times and influence of government policies as well as impact of modern day science and technology in the advancement of herbal medicine, in efforts to achieve the goals of catering for the needs of human health and wellness.

Scientific search engines such as PubMed, Medline, EMBASE, Mendeley, Google Scholar, ScienceDirect and SpringerLink were used to retrieve online publications from 1983 to 2012. Keywords such as 'herbal medicines', 'pre-historic herbal medicines', 'traditional medicine practices', 'herb toxicity', and 'phytomedicine' were used to collate relevant articles. The results were then cross-referenced to generate a total number of 53 references cited in this review.

\section{History of herbal medicine}

People worldwide have been using herbal medicine for the treatment, control and management of variety of ailments since prehistoric times [3-6]. There is ample archaeological evidence to support the fact that primitive man used plant and herbs for medicinal purposes. For instance, pollen analyses of numerous plants found in the grave of Neanderthal man buried 60,000 years ago in Iraq indicated that the plants buried with the corpse were all of medicinal value $[3,5]$. In another instance, medicinal herbs found in the personal belongings of the 'Ice Man' whose body was frozen in the Swiss Alps for more than 5,300 years are thought to have been used to treat the parasites found in his intestine $[3,5]$.

Other sources also provide ample historical evidence of man's use of plants for medicinal purposes over in antiquity. For example, the Sumerian clay tablet, dated about 5,000 years ago, recorded and described the medicinal uses of plants such as laurel, caraway and thyme by the ancient Sumerian of Mesopotamia [2,5,6]. These plants are still used all over the world for medicinal purposes. The Ebers papyrus, written about 3,500 years ago points to the fact that ancient Egyptians used plants such as mandrake for pain relief and garlic for the treatment of heart and circulatory disorders [5]. The Old Testament of the Bible (Ezekiel 47:12) also mentioned the use of plants for medicinal purposes [7,8]. Ancient China is also a source of information about the early use of medicinal plants. 'The Pen Tsao' (Canon of Herbs) a Chinese pharmacopoeia published about 1600 BC contains list of several medicinal plants and their uses- including MaHuang, the shrub that introduced the drug ephedrine to modern medicine [4]. In India herbal medicine, the Rig-Veda, a collection of Hindu sacred verses, contains most aspects of Vedic science such as yoga, meditation, mantra and Ayurveda, which are still widely practiced today [9]. 


\section{Ancient western world traditional medicine systems}

In the ancient western world, the development of western medicine is believed to have been influenced by the writing of Greek philosophers, in particular, Hippocrates (460-377 BC) and Aristotle (384-322 BC), and the works of Dioscorides, who compiled information on more than 600 plant species with medicinal value in his famous book 'De Materia Medica'. This book, which was written in the first century $\mathrm{AD}$, remained the standard reference in most of Europe for more than 1,500 years [5,10]. During the Renaissance (476-1500 AD) and the Middle Ages herbal medicine played an important role in health care management [11]. Additionally, the monasteries preserved information about herbal remedies in countries such as England, Ireland and Germany [4]. At the same time, the Arabs preserved much of the Greco-Roman expertise, and expanded it to include the use of their own resources, together with those of the Chinese and Indian, which was unknown to the Greco-Roman world [6]. In the United States, herbal traditions brought by the European settlers were merged with those acquired from native Americans, until the early 1900s when expansion of the pharmaceutical industries, coupled with the advancement in analytical techniques as well as increased knowledge of synthetic chemistry, led to a decline of herbal medicine practices in the in the developed world [4].

\section{Evaluation of some African medicinal plants}

Little is known about African traditional medicine in particular and the use of herbal medicine by ancient African people. Although it is difficult to state the exact period the use of medicinal plants originated in Africa, the likely earliest time was circa $1770 \mathrm{BC}$ in the code of Hammurabi (Babylon) and $1550 \mathrm{BC}$ in Egypt [2]. This is because African traditional systems of medicine are poorly recorded and, to a large extent, remain so to date [12-14]. African traditional systems of medicine were once believed to be primitive and wrongly derided by foreign religions especially during the colonial rule in Africa and subsequently by conventional or orthodox medicine practitioners [14]. Despite the suppression by the colonial rulers and the negative attitudes of the orthodox practitioners, traditional healers and herbalists in Africa continued to dispense herbal remedies [12,13]. Collaborative ethnobotanical studies, and subsequent experimental evaluation have confirmed the therapeutic potential of some African medicinal plants such as Acacia senegal (Gum Arabic), Agathosma betulna (Buchu), Aloe ferax (Cape Aloes), Aloe vera (North African Origin), Artemisia afra (African Wormwood), Aspalanthus linearis (Rooibos tea), Catha edulis (Khat), Commiphora myrrha (Myrrh), Harpagophytum procumbens (Devils Claws), Hypaxis hamerocallidea (African potato) and Catharanthus roseus (Rosy Periwinkle) [13,15]. Several authors have also reviewed the ethnomedical uses of several plants which were highly valued by ancient Egyptians and are still in use today [16-19].

\section{Herbal medicine during the 19th and 20th centuries}

Prior to the 19th century, plant medicines were administered in their crude form as infusions (herbal teas), tinctures (alcoholic extracts), decoctions (boiled extracts of roots or stem bark), and syrup or applied externally as ointments (poultices, balms and essential oils) and herbal baths $[3,20]$. However, from the late 19th century onwards, scientists began the isolation, purification and identification of bioactive principles from medicinal plants. This endeavour led to the discovery of some of the most important drugs that are still widely used in modern medicine $[5,10,21,22]$. For instance, morphine isolated from opium poppy (Papaver somniferum) is a powerful pain reliever and narcotic; quinine isolated from Cinchona plant species is an effective antimalarial drug; taxol (isolated from Taxus brevifolius) and vincristine (isolated from Catharanthus rosesus) are highly effective against certain cancers. Also, serpentine (isolated from the root of the Indian plant Rauwolfia serpentia) is used for the treatment of hypertension [20-23].

In addition to the biologically-active plant-derived natural products, many other plant bioactive principles had served as lead compounds for the design, synthesis and development of novel drugs $[4,21,23,24]$. In this contest, some plant derived natural products have been slightly modified to render them more effective or less toxic $[4,5]$. For instance, aspirin was developed in 1953 through structural modification of salicylic acid, which was identified as the active principle in a number of plants known for their pain relieving properties $[5,23]$. In the same way, due to the poor bioavailability of the anti-malarial agent artemisinin, which limits its effectiveness, various derivatives have been developed. These include artesunate, artemether, arteether and artemether. The earliest and famous discovery of an effective antimalarial agent-quinine was obtained from Cinchona officinalis bark dates back to 1638. In another example, the development of the current and popular oral hypoglycemic agentmetformin was based on the use of goat's rue (Galega officinalis) to treat diabetes [4]. The blood glucose lowering property of $G$. officinalis has been attributed to the presence of a guanidine-type of alkaloidgalegine. However, galegine was found to be toxic for human use, and therefore, several structural analogs were synthesized and clinic trials confirmed its efficacy. These efforts culminated to the development and marketing of metformin as an effective anti-diabetic drug $[4,22]$.

\section{Contemporary issues on herbal medicine}

Although the direct use of plant extracts in developed countries continued to decline in the late 19th and early 20th centuries, medicinal plants still play a key role in health care system of many parts of the world $[5,25]$. However, the use of herbal supplements has increased dramatically over the past 30 years and most commonly used medicinal plants in the United States have been reviewed $[1,26]$. According to World Health Organization (WHO) [27] 60\% of the world's population depends on traditional medicine and $80 \%$ of the population in developing countries depends almost entirely on traditional medicine practices and herbal medicines for their primary health care needs $[19,28]$. Furthermore, at the beginning of the $21 \mathrm{st}$ century, the worldwide annual market for herbal medicinal products approached US\$ 60 billion [29] and the long tradition of herbal medicine continues to the present day in China, Indian and many countries in Africa and South America [5,19,25,28,30]. In many village marketplaces of these countries, medicinal herbs are sold alongside vegetables and other wares. Practitioners of herb medicines in developing countries often undergo a rigorous and extended training to learn the names, uses, and preparation of native plants [14].

\section{Traditional medicine agenda for developing countries}

In order to achieve "health for all", an effective health agenda must ensure that Western medicine is complemented with traditional medicine [19,31]. Accordingly, African Head of States declared the first ten years of the millennium (2001-2010) as the 'Decade of Traditional Medicine in Africa' that is commemorated on 31st August of every year [13,27]. This was renewed for the period 2011-2020 and the recent adoption of the Traditional Health Practitioner's Bill by the 
South African legislature and commemoration of African Traditional Medicine day in Cameroon are testimonies to the fact that African governments are committed to ensuring the integration of traditional medicine into African health care systems [30,32]. For instance, the WHO in collaboration with the Cameroonian government has put in place a strategic platform for the practice and development of traditional medicine in Cameroon, with a view to harmonizing the traditional medicine practice through the creation of synergy between traditional and modern medicine practices and institutionalization of more harmonized integrated traditional medicine practices by the year 2012 [30]. In attempt to create a sustainable synergy between traditional and modern medicine practices, the WHO is now engaged in the establishment of definitive guidelines for scientific methodology of clinical research and the re-appraisal of effectiveness of herbal medicine. Couple of years ago, the Nigerian Government established a national committee on traditional medicine with the expressed desire to boost Nigeria's market share of traditional medicine [33]. These efforts are further complimented by huge investments in medicinal plant research in China, India, Nigeria, and the United States by the WHO [29] as well as renewed interest in prospecting for medicinal plants by multinational pharmaceutical companies.

In the developed countries, it has been reported that sufferers of chronic diseases are turning to herbal remedies as alternative to modern synthetic drugs [34]. This renewed interest in the use of herbal medicine is believed to be motivated by several factors including:

Unsubstantiated concerns to side effects of modern drugs: Although synthetic drugs exhibit quicker efficacy, there are at present, unsubstantiated opinion of higher incidents of adverse reactions following the use modern drugs when compared with herbal remedies [35-39].

Accessibility and availability of herbal remedies: Herbal remedies are readily available and accessible for both practitioners and especially patients in remote rural areas [19,30,31,34].

High cost of synthetic drugs: Medicinal plants used for remedies are comparatively less expensive when compared with orthodox/synthetic drugs [19].

Cultural factors: From a cultural perspective, traditional medicine has always been considered as an efficient and acceptable option even when modern health facilities are available. As a result of recent advances in biochemistry, immunology, medical botany and pharmacognosy, research findings have established the descriptive capacity, effectiveness and rationality of herbal medicines.

\section{Research efforts on herbal medicine}

The uses of drugs and dietary supplements derived from plants have accelerated in recent years. Pharmacologist, microbiologist, biochemist, botanist and natural product chemists are currently investigating medicinal plants for phytochemicals and lead compounds that could be developed for the treatment of several ailments $[30,40,41]$, as exemplified by the plethora of publications of scientific research papers in many reputable journals. Most of these research exercises cover the areas of bio-analytical methodology, isolation, purification and characterization of the bioactive principles of medicinal plants. Furthermore, research efforts in herbal medicine are now focused on the identification of phytochemicals and elucidation of their molecular structures, and more recently, establishing their mechanism of action and potential toxicological properties. For instance, Tanaka et al., [42] employed spectroscopic data to identify five phytosterols, namely, lophenol, 24-methyllophenol, 24-ethyllophenol, cycloartanol, and 24-methylene cycloartanol as the major anti-hyperglycemic phytochemicals in $A$. vera gel using Type II diabetic BKS.Cg-m $(+/+) \operatorname{Lepr}(\mathrm{db} / \mathrm{J})(\mathrm{db} / \mathrm{db})$ mice.

Based on the outcomes of herbal medicine research over the years, the 21st century has seen a paradigm shift towards therapeutic standardization of herbal drugs, of which their efficacies have been supported and confirmed through clinical trials [43]. A potentially farreaching observation in terms of the safety concerns of consuming certain herbal medicine has been also evaluated and documented using in vitro and in vivo methods $[37,44]$.

\section{Herbal medicine: safety concerns, prospects and handicaps}

The worldwide phytomedicine markets, in addition to the control and regulatory measures on the manufacture, distribution and sale of herbal medicine as well as safety concerns have been reviewed [1,37]. As a result of increasing demand for herbal healthcare products and application of traditional medicine, also referred to as complementary and alternative medicine systems, in both developing and developed countries, there are increasing concerns about the safety, standardization, efficacy, quality, availability and preservation of herbal products by policy-makers, health professionals and the general public. The problems associated with regulation, standardization and quality assurance in the manufacture of herbal medicines are prevalent both in developed and developing countries of the world $[2,45,46]$.

\section{Standardization and regulatory measures of herbal medicinal products}

Standardization of herbal medicines is often a very difficult task because of the complexity of their diverse secondary metabolites, with therapeutic actions that may depend largely on age, genetic factors and geographical location of the plant species [47]. The variability in phytochemical contents amongst varieties of herbal products from the same plant species engenders profound differences in pharmacological activity. Also, the harvesting process and period, coupled with incidents of adulterations due to the presence of microorganisms and pesticides have profound impact on achieving uniform standards of herbal medicines worldwide [48]. Improvement in the quality of herbal medicines could be achieved by deliberate implementation of good agricultural practices (GAPs) at the point of cultivation of medicinal plants and good manufacturing practices (GMPs) during the process of manufacture and packaging of finished herbal products, as well as post-marketing quality assurance surveillance [48].

Additionally, for greater healthcare value and for commercial benefits, these concerns have to be allayed by carrying out cutting edge research to investigate these perceived drawbacks of the use of herbal remedies and the findings made available to the public. In this regard, records show that robust phytochemical and pharmacological research activities on medicinal plants and herbal medicines are actively going on in reputable Research Institutes and Universities, and efforts are being made to isolate and identify bioactive chemical constituents and to substantiate the claims of their efficacy and safety. Therefore, the presence of a vast array of phytochemicals in herbal medicines has opened up intense research activities involving the characterization of new chemical constituents, the identification and structure elucidation, biosynthesis and chemical reactivity of bioactive principles. Interestingly, life scientists are now been engaged in 
Research Institutes and Universities in view of current trends in herbal medications, in order to ensure the dissemination of expertise in the analysis, uses, and recent issues on potential toxicity of herbal remedies for informed decisions and guides to herbal medicinal practice. Accordingly, most scientific evidence from randomized clinical trials has shown favourable outcomes in respect of the use of many herbal remedies [49]. Furthermore, the so-called Omic techniques have unravel the complicity associated with the understanding of mechanism of action of herbal bioactive principles, which has introduced vistas of scientific methods for the modernization and standardization of several Chinese herbal medicines [50]. It is worthwhile to note that new approaches and insights into Chinese herbal medicine through Research and Development (R\&D) have led to the development of numerous traditional remedies and innovative drug discovery systems [51], which will make great impact on the mainstream biomedical science $[52,53]$.

Aside the use of scientific methods to ensuring the quality and safety of herbal remedies, the integration of control measures during the course of production, storage and sale, which conforms to extant rules and regulations should be officially and legally applied using established Government institutions and legislative instruments. Unfortunately, in the absence of stricter regulatory controls the production and sale of herbal medicines in developing countries is a major drawback of traditional medicine.

\section{Conclusion}

In spite of the increasing demand for herbal medicines for the alleviation/management of diseases, as well as improvement of general well-being, there still remain several challenges that are hindering the efforts being made to integrate it into national health systems. Among the key challenges are poor quality control and lack of standardization, lack of pharmacological and clinical data on majority of herbal products to ascertain efficacy and address concerns about toxicity.

Nevertheless, following recent renewed interest in medicinal plant research and the use of cutting-edge analytical techniques and well thought-out research methodologies, the prospects of advancing the frontiers of knowledge in herbal medicine is now at an all-time high. Additionally, following the current sustained improvements in quality control and regulatory measures in many countries of the world, it is envisaged that in the near future, herbal medicine will be integrated into conventional medical systems.

\section{References}

1. Bent S1 (2008) Herbal medicine in the United States: review of efficacy, safety, and regulation: grand rounds at University of California, San Francisco Medical Center. J Gen Intern Med 23: 854-859.

2. Falodun A (2010) Herbal medicine in Africa-distribution, standardization and prospects. Res J Phytochem 4: 154-161.

3. Griggs B (1981) Green pharmacy: A history of herbal medicine. J Morman \& Hobhouse Ltd. London.

4. Kinghorn AD, Balandrin MF (1993) Human Medicinal Agents from Plants. America Chemical Society. San Francisco. USA.

5. Kong JM, Goh NK, Chia LS, Chia TF (2003) Recent advances in traditional plant drugs and orchids. Acta Pharmacol Sin 24: 7-21.

6. Philipeon JD (2003) Phytochemistry and medicinal plants. Phytother 56: 237-243.

7. Duke JA (1983) Medicinal plants of the Bible. Trado-Medic Book. Conch Magazine Ltd. New York.
8. Zand J, Rountre R, Walton R (1994) Smart medicine for a healthier child. Avery Publishing Group. Garden City Park. New York.

9. Grover JK, Yadav S, Vats V (2002) Medicinal plants of India with antidiabetic potential. J Ethnopharmacol 81: 81-100.

10. Goldman P1 (2001) Herbal medicines today and the roots of modern pharmacology. Ann Intern Med 135: 594-600.

11. Brater DC, Daly WJ (2000) Clinical pharmacology in the Middle Ages: principles that presage the 21st century. Clin Pharmacol Ther 67: $447-450$.

12. Sowofora A (1993) Medicinal plants and traditional medicine in Africa. 2nd Edition. Spectrum Books. Ibadan. Nigeria. pp 26-100.

13. Elujoba AA, Odeleye OM, Ogunyemi CM (2005) Traditional medicine development for medicinal and dental primary care delivery system in Africa. Afr J Tradit Compl Altern Med 2: 46-61.

14. Okigbo RN, Mmeka EC (2006) An appraisal of phytomedicine in Africa. KMITL Sci Tech J 6: 83-93.

15. van Wyk B-E, van Oudtshoorn B, Gericke N (1997) Medicinal plants of South Africa. 2nd Edition. Briza Publication. Pretoria. South Africa.

16. Hammouda FM, Ismail SI, Abdel-Azim NS, Shams KA, Batanounny KH (2005) Guide to medicinal plants in North Africa. IUCN Center for Mediterranean Cooperation, Malaga, Spain.

17. Hamed AR, Abdel-Shafeek KA, Abdel-Azim NS, Ismail SI, Hammouda FM (2007) Chemical Investigation of Some Capparis Species Growing in Egypt and their Antioxidant Activity. Evid Based Complement Alternat Med 4: 25-28.

18. Mahmoud SM, Abdel-Azim NS, Shahat AA, Ismail SI, Hammouda FM (2007) Phytochemical and biological studies on Verboscum sinaiticum Benth growing in Egypt. Nat Prod Sci 12:186-189.

19. Abdel-Azim NS, Shams KA, Shahat AAA, El-Missiry MM, Ismail SI et al. (2011) Egyptian herbal drug industry: challenges and future prospects. Res J Med Plant 5: 136-144.

20. Gurib-Fakim A (2006) Medicinal plants: traditions of yesterday and drugs of tomorrow. Mol Aspects Med 27: 1-93.

21. Newman DJ, Cragg GM, Snader KM (2003) Natural products as sources of new drugs over the period 1981-2002. J Nat Prod 66: 1022-1037.

22. Gupta R, Gabrielsen B, Ferguson SM (2005) Nature's medicines: traditional knowledge and intellectual property management. Case studies from the National Institutes of Health (NIH), USA. Curr Drug Discov Technol 2: 203-219.

23. Lesney MS (2004) Nature's pharmaceuticals: Natural products from plants remain at the core of modern medicinal chemistry. TCAW 13: 26-31.

24. UNESCO FIT/504-RAF-48 (1998) Terminal reports: Promotion of ethnobotany and the sustainable use of plant resources in Africa. Paris. pp.60.

25. Tapsell LC, Hemphill I, Cobiac L, Patch CS, Sullivan DR, et al. (2006) Health benefits of herbs and spices: the past, the present, the future. Med J Aust 185: S4-24.

26. http://umm.edu/health/medical/altmed/treatment/herbal-medicine [accessed on 25 February 2015].

27. WHO (2001) Legal status of traditional medicines and complimentary/ alternative medicine: worldwide review. WHO Publications pp.10-14.

28. Zhang BB, Moller DE (2000) New approaches in the treatment of type 2 diabetes. Curr Opin Chem Biol 4: 461-467.

29. Tilburt JC, Kaptchuk TJ (2008) Herbal medicine research and global health: an ethical analysis. Bull World Health Organ 86: 594-599.

30. Fokunang CN, Ndikum V, Tabi OY, Jiofack RB, Ngameni B, et al. (2011) Traditional medicine: past, present and future research and development prospects and integration in the National Health System of Cameroon. Afr J Tradit Complement Altern Med 8: 284-295.

31. WHO (2002) Traditional medicinal strategy 2002-2005. WHO Publication pp. 1-6.

32. Department of Health (2004) Traditional health practitioners' bill. Available from: http://www.doh.gov.za/docs/index.html [accessed on 25 February 2015]. 
33. Adelaja A (2006) Nigeria boosts research into traditional medicine. Available from: http://www.scidev.net/en/news/nigeria-boosts-researchinto-traditional-medicine.html [accessed on 25 February 2015].

34. Calixto JB (2000) Efficacy, safety, quality control, marketing and regulatory guidelines for herbal medicines (phytotherapeutic agents). Braz J Med Biol Res 33: 179-189.

35. Piédrola G, Novo E, Escobar F, García-Robles R (2001) White blood cell count and insulin resistance in patients with coronary artery disease. Ann Endocrinol (Paris) 62: 7-10.

36. Yaryura-Tobias JA, Pinto A, Neziroglu F (2001) Anorexia nervosa, diabetes mellitus, brain atrophy, and fatty liver. Int J Eat Disord 30: 350-353.

37. Haq J (2004) Safety of medicinal plants. Pak J Med Res 43: 8 pages.

38. Gardhipuram PSK, Durairaji SK, Sorimuthu PS (2006) Anti-diabetic activity of fruits of Terminalia chebula on streptozotocin-induced diabetic rats. J Health Sci 54: 283-291.

39. Aronson JK (2009) Side effects of herbal medicines. Elsevier B.V. Amsterdam, Boston, Heidelberg.

40. Jiofack T, Ayissi I (2006) Floristic evaluation of the Upper Nyong valley in Cameroon, Technical report. Cameroon Wildlife Conserv Soc 3: 50.

41. Acharya D, Shrivastava A (2008) Indigenous Herbal Medicines: Tribal Formulations and Traditional Herbal Practices. 1stedn., Aavishkar Publishers, Jaipur-India. pp. 440.

42. Tanaka M, Misawa E, Ito Y, Habara N, Nomaguchi K, et al. (2006) Identification of five phytosterols from Aloe vera gel as anti-diabetic compounds. Biol Pharm Bull 29: 1418-1422.

43. Alvari A, Mehrnaz SO, Ahmad FJ, Abdin MZ (2012) Contemporary overview on clinical trials and future prospects of hepato-protective herbal medicines. Rev Recent Clin Trials 7: 214-223.
44. van de Venter M, Roux S, Bungu LC, Louw J, Crouch NR, et al. (2008) Antidiabetic screening and scoring of 11 plants traditionally used in South Africa. J Ethnopharmacol 119: 81-86.

45. Rotblatt MD1 (1999) Herbal medicine: a practical guide to safety and quality assurance. West J Med 171: 172-175.

46. Sane RT (2002) Standardization, quality control and GMP for herbal drugs. Indian Drug 39: 184-190.

47. Firenzuoli F, Gori L (2007) Herbal medicine today: clinical and research issues. Evid Based Complement Alternat Med 4: 37-40.

48. Fong HH1 (2002) Integration of herbal medicine into modern medical practices: issues and prospects. Integr Cancer Ther 1: 287-293.

49. Bubela $\mathrm{T}$, Boon H, Caulfield $\mathrm{T}$ (2008) Herbal remedy clinical trials in the media: a comparison with the coverage of conventional pharmaceuticals. BMC Med 6: 35.

50. Buriani A, Garcia-Bermejo ML, Bosisio E, Xu Q, Li H, et al. (2012) Omic techniques in systems biology approaches to traditional Chinese medicine research: present and future. J Ethnopharmacol 140: 535-544.

51. Pan SY, Chen SB, Dong HG, Yu ZL, Dong JC, et al. (2011) New perspectives on chinese herbal medicine (zhong-yao) research and development. Evid Based Complement Alternat Med 2011: 403709.

52. Trusheim MR, Berndt ER, Douglas FL (2007) Stratified medicine: strategic and economic implications of combining drugs and clinical biomarkers. Nat Rev Drug Discov 6: 287-293.

53. Parekh HS, Liu G, Wei MQ (2009) A new dawn for the use of traditional Chinese medicine in cancer therapy. Mol Cancer 8: 21. 